Roche, UCB, Speakers bureau: Consultancy / speaker fees from: Abbvie, BMS, Celgene, Lilly, MSD, Novartis, Pfizer, Roche, UCB, Valeria Rios Rodriguez Consultant of: Abbvie, Novartis, Martin Rudwaleit Consultant of: AbbVie, BMS, Celgene, Janssen, Eli Lilly, MSD, Novartis, Pfizer, Roche, UCB Pharma, Denis Poddubnyy Grant/ research support from: AbbVie, MSD, Novartis, and Pfizer, Consultant of: AbbVie, Bristol-Myers Squibb, Eli Lilly, MSD, Novartis, Pfizer, Roche, UCB, Speakers bureau: AbbVie, Bristol-Myers Squibb, Eli Lilly, MSD, Novartis, Pfizer, Roche, UCB DOI: 10.1136/annrheumdis-2020-eular.4862

\section{AB0717 THE ASAS-HEALTH INDEX MAY BE USEFUL TO IDENTIFY DISEASE ACTIVITY STATES IN PATIENTS WITH SPONDYLOARTHRITIS.}

S. Alonso Castro ${ }^{1}$, E. Pardo Campo ${ }^{1}$, L. C. Charca Benavente ${ }^{1}$, M. Pino Martínez ${ }^{1}$, S. Fernández ${ }^{1}$, L. M. Arboleya Rodríguez¹ , M. Alperi-López ${ }^{1}$, R. Queiró Silva ${ }^{1} \cdot{ }^{1}$ Hospital Universitario Central de Asturias, Rheumatology, OVIEDO, Spain

Background: Patients with spondyloarthritis (SpA) suffer not only from pain or physical disability, but they are also affected in multiple facets of life due to this condition (disease impact). Recently, the ASAS group has proposed a new way of capturing the impact that SpA have on patients' lives, based on the principles proposed by the International classification of functioning, disability and health (ICF). The tool obtained (ASAS-health index or ASAS-HI) includes 17 items that cover most ICF domains.

Objectives: To analyze the performance of ASAS-HI in real clinical practice, by comparing it with other standard measures of evaluation of SpA. To assess whether ASAS-HI is able to identify disease activity states in these patients.

Methods: This cross-sectional study included 111 consecutive patients with SpA (ASAS criteria). The correlation (Spearman's rho) between ASAS-HI, BASDAI, ASDAS, and BASFI was analyzed. ROC curves were constructed to analyze ASAS-HI values that determined BASDAI remission, ASDAS inactive disease, and ASDAS low activity. A logistic regression was made to determine the ASAS-HI items with greater capability to discriminate the state of remission / inactive disease.

Results: Seventy-four men and 37 women were included, mean age of $43.3 \pm 10.6$ years. The average duration of illness was $7.6 \pm 6.8$ years. Sixty percent of the series was under biological therapy. HLA-B27 was positive in $79.3 \%$. The average value of ASAS-HI was $5.4 \pm 3.8$. There were significant correlations between ASDAS and BASDAI (rho: 0.89, $p<0.0005$ ), BASDAI and BASFI (rho: 0.86, $p<0.0005$ ), BASFI and ASDAS (rho: $0.78, p<0.0005$ ), BASDAI and ASAS-HI (rho: $0.77, p<0.0005$ ), ASDAS and ASAS-HI (rho: 0.70, $\mathrm{p}<0.0005$ ). The optimal cut-off point of ASAS-HI for BASDAI remission (Table 1) corresponded to a value $\leq 2$. As for the value of ASAS-HI to define ASDAS inactive disease (Table 2), this was $\leq 0$. For ASDAS low activity, the value was $\leq 6$ [area under the ROC curve 0.82 (95\% Cl: 0.73-0.89), Sen: $89.5 \%$, Spe: 66.1). In the multivariate regression, the two ASAS-HI items associated with BASDAI non-remission were, "I often get frustrated" [OR 9.2 (95\% Cl: 1.2-69.4), p = 0.032], and "I sleep badly at night" [OR $7.7(95 \% \mathrm{Cl}$ : 1.4-41.6), $\mathrm{p}=0.018)$. As for ASDAS, the only question of ASAS-HI significantly associated with active disease was "pain sometimes disrupts my normal activities" [OR 8.7 (95\% Cl: 1.7-45.2), $p=0.010]$.

Conclusion: ASAS-HI correlates well with most outcome measures in SpA. A cutoff point of ASAS-HI $\leq 6$ identifies a low disease activity and could be considered a good treatment objective. The evaluation of SpA should include not only conventional measures (BASDAI / ASDAS) but also disease impact measures (ASAS-HI).

Table 1.

$\begin{array}{llllll}\text { Area under the ROC curve (AUC) } & 0.883 & 95 \% \mathrm{Cl} & 0.809-0.936 & \text { p-value } & <0.000\end{array}$ $\begin{array}{lccccc}\text { Optimal cut-off point } & \leq 2 & \text { Sensitivity } & 65.71 & \text { Specificity } & 96.05\end{array}$

Table 2.

$\begin{array}{llllll}\text { Area under the ROC curve (AUC) } & 0.873 & 95 \% \mathrm{Cl} & 0.797-0.929 & \text { p-value } & <0.0001\end{array}$ $\begin{array}{llllll}\text { Optimal cut-off point } & \leq 0 & \text { Sensitivity } & 58.82 & \text { Specificity } & 94.68\end{array}$

Disclosure of Interests: None declared

DOI: 10.1136/annrheumdis-2020-eular.4892

\begin{tabular}{|l|l}
\hline AB0718 & DIAGNOSTIC PERFORMANCE OF VARIOUS \\
CLASSIFICATION CRITERIA IN LOW BACK \\
PAIN PATIENTS WITH SUSPECTED AXIAL \\
SPONDYLOARTHRITIS: A PRAGMATIC STUDY
\end{tabular}

A. Ramon ${ }^{1}$, C. Fayolle ${ }^{2}$, H. Devilliers ${ }^{3}$, C. Piroth ${ }^{4}$, I. Herrada ${ }^{4}$, G. Attane ${ }^{5}$, D. Wendling ${ }^{6}$, P. Ornetti ${ }^{4} .{ }^{1}$ Dijon University Hospital, Rheumatology, DIJON, France; ${ }^{2}$ Dijon University Hospital, Rheumatology, DIJON, France; ${ }^{3}$ Dijon University Hospital, Internal Medicine, Dijon, France; ${ }^{4}$ Dijon University Hospital, Rheumatology, Dijon, France; ${ }^{5}$ Dijon University Hospital, Radiology, Dijon, France; ${ }^{6}$ Besançon University Hospital, Rheumatology, Besançon, France
Background: In routine practice, axial spondyloarthritis ( $\mathrm{SpA}$ ) can be a diagnostic challenge because there is potential overlap with osteoarthritic low back pain or diffuse polyalgic syndrome with axial pain as fibromyalgia. Internationally recognized classification criteria (AMOR, ASAS (1), ESSG (2)) are often used as diagnostic tools in clinical practice (3), but few studies have sought to establish their "real life" diagnostic performances.

Objectives: This monocentric study aimed to evaluate the diagnostic performance of different sets of classification criteria for $\mathrm{SpA}$ in patients with chronic back pain hospitalized for suspected axial SpA. The second objective was to evaluate the impact of the sacroiliac MRI reading according to the ASAS MRI reading or expert musculoskeletal reading.

Methods: Patients presenting with inflammatory low back pain who underwent standardized sacroiliac MRI protocol were consecutively included. The diagnoses obtained with the classification criteria (AMOR, ESSG, Modified AMOR and Mod ified ESSG (with sacroiliac MRI)) were compared to the gold standard diagnoses (made by a college of three experienced rheumatologists). Two readings of the sacroiliac MRI were performed (ASAS MRI reading and Expert MRI reading (including all inflammatory or structural T1 or T2 STIR abnormalities)). Diagnostic performance was measured for each set of classification criteria: sensitivity, specificity, predictive positive and negative values (PPV, NPV) and positive and negative likelihood ratios (PLR, PLN). The clinical, biological and MRI factors associated with axial SpA diagnosis were identified in a multivariate logistic regression model.

Results: 83 patients were included of which 27 had axial SpA according to the opinion of the college of rheumatologists. The AMOR modified criteria (with ASAS MR reading) had the highest diagnostic performance values, with sensitivity $=96 \%$, specificity $=71 \%$, NPV $=97 \%$, PPV $=54 \%$, PLR $=3.3$, and NLR $=0.06$. Sacroiliac MR reading demonstrated poor sensitivity $(<60 \%)$ for SpA (ASAS or expert reading), while expert reading of MRI had high specificity (98\%), NPV $=90 \%, \mathrm{PPV}=78 \%$, and $\mathrm{PLR}=18$. In multivariate logistic regression, the presence of enthesitis (OR $=3.51$ IC95\% [1.10;11.21]; $p=0.024$ ), positive HLA B27 (OR = 4.22, IC95\% [1.25;14.18]; $p$ $=0.02)$ ) or sacroiliitis on MRI (ASAS reading) (OR = 3.34, IC95\% $[1.04 ; 10.76] ; p=$ 0.043) were independently associated with the final diagnosis of SpA

Conclusion: The results of this pragmatic study suggest that the Modified AMOR criteria with ASAS MRI reading can be used to rule out axial spondyloarthritis (NPV $=97 \%$ ). However, the use of an MRI ASAS reading alone creates a risk of false positives because of the greater impact on ASAS criteria compared to AMOR or ESSG criteria. Further international studies are needed to decrease the rate of false positives in suspected cases of axial spondyloarthritis in routine practice.

References:

[1] Dougados M, van der Linden S, Juhlin R et al. The European Spondylarthropathy Study Group preliminary criteria for the classification of spondylarthropathy. Arthritis Rheum 1991;34:1218-27.

[2] Rudwaleit $M$, van der Heijde $D$, Landewé $R$ et al. The development of Assessment of SpondyloArthritis international Society classification criteria for axial spondyloarthritis (part II): validation and final selection. Ann Rheum Dis. 2009;68:777-83.

[3] Gazeau P, Cornec D, Timsit MA et al. Classification criteria versus physician's opinion for considering a patient with inflammatory back pain as suffering from spondyloarthritis. Joint Bone Spine 2018;85:85-91.

Disclosure of Interests: None declared

DOI: 10.1136/annrheumdis-2020-eular.2351

\section{$\mathrm{AB} 0719$ \\ CLINICAL FEATURES OF PATIENTS WITH ANKYLOSING SPONDYLITIS AND SECONDARY AA-AMYLOIDOSIS}

D. Rumiantceva ${ }^{1}$, E. Agafonova ${ }^{1}$, S. Krasnenko ${ }^{1}$, M. Podryadnova ${ }^{1}$,

A. Starkova ${ }^{1}$, M. Urumova ${ }^{1}$, S. Erdes ${ }^{1} .{ }^{1}$ V.A. Nasonova Research institute of Rheumatology, Moscow, Russian Federation

Background: Secondary AA-amyloidosis is one of the most serious complications of ankylosing spondylitis (AS). Better knowledge of specific to secondary AA-amyloidosis clinical features is important for improving further management of these patients.

Objectives: To conduct a comparative analysis of AS patients with and without secondary AA-amyloidosis.

Methods: The study included 220 AS patients (according to modified New York criteria) without amyloidosis - Group 1, and 9 AS patients with histologically confirmed secondary AA-amyloidosis - Group 2.

Results: Table 1 presents the comparative characteristics of Group 1 and Group 2 patients. Both groups were comparable in terms of patients' age, rates of HLA B27 positivity, presence of enthesitis, uveitis, inflammatory bowel diseases (IBD), and psoriasis on assessment. Group 2 patients tended to be younger at AS onset, while shorter disease duration and fewer male patients were established for Group 1. Group 2 had higher rates of extra-spinal AS manifestations, such as arthritis and coxitis. It should be noted that all AS patients with secondary AA-amyloidosis were males, with clinically manifest arthritis, involving hip joints, and AS onset in the childhood in 8 out of 9 cases. 
Table 1. Comparative characteristics of Group 1 and Group 2 AS patients.

\begin{tabular}{lccc}
\hline & Group 1 (n=220) & Group 2 (n=9) & p \\
\hline Mean age, M \pm a, y. & $35,1 \pm 9,5$ & $40,1 \pm 8,6$ & $>0.05$ \\
Mean age at the onset, $\mathrm{M} \pm$ a, y. & $29,9 \pm 9,6$ & $13,4 \pm 7,5$ & $<\mathbf{0 . 0 5}$ \\
Mean disease duration, $\mathrm{M} \pm \mathrm{a}, \mathrm{y}$. & $6,9 \pm 5,6$ & $26,3 \pm 6,5$ & $<\mathbf{0 . 0 5}$ \\
Men, $\mathrm{n}(\%)$ & $162(73,6 \%)$ & $9(100 \%)$ & $<\mathbf{0 . 0 5}$ \\
HLA B27, $\mathrm{n}(\%)$ & $202(91,8 \%)$ & $9(100 \%)$ & $>0.05$ \\
Arthritis, $\mathrm{n}(\%)$ & $182(82,7 \%)$ & $9(100 \%)$ & $<\mathbf{0 . 0 5}$ \\
Coxitis, $\mathrm{n}(\%)$ & $119(54,0 \%)$ & $9(100 \%)$ & $<\mathbf{0 . 0 5}$ \\
Enthesitis, $\mathrm{n}(\%)$ & $105(47,7 \%)$ & $7(78 \%)$ & $>0.05$ \\
Uveitis, $\mathrm{n}(\%)$ & $52(23,6 \%)$ & $4(44,4 \%)$ & $>0.05$ \\
IBD, $\mathrm{n}(\%)$ & $5(2,2 \%)$ & 0 & $>0.05$ \\
Psoriasis, $\mathrm{n}(\%)$ & $24(10,9 \%)$ & 0 & $>0.05$ \\
\hline
\end{tabular}

Conclusion: Patients with AS and secondary AA amyloidosis are predominantly of male gender, who usually get sick in childhood, have 100\% HLA-B27 positivity, peripheral arthritis, and coxitis.

Disclosure of Interests: None declared

DOI: 10.1136/annrheumdis-2020-eular.3209

\section{AB0720 SOLUBLE TRANSFERRIN RECEPTOR IN DIAGNOSIS OF IRON DEFICIENCY ANEMIA IN PATIENTS WITH SPONDYLOARTHRITIS}

K. Safarova ${ }^{1}$, A. Rebrov ${ }^{2} .{ }^{1}$ Saratov State Medical University named after V.I. Razumovsky, Chair of Hospital Therapy, Saratov, Russian Federation; ${ }^{2}$ Saratov State Medical University named after V.I. Razumovsky, Chair of Hospital Therapy, Saratov, Russian Federation

Background: Anemia is a frequent hematological disorder in patients with rheumatic diseases. The main pathogenetic variants of anemia are anemia of chronic disease (ACD), iron deficiency anemia (IDA), and anemia of chronic disease with iron deficiency (ACD/IDA). The presence of systemic inflammation hinders to diagnose absolute iron deficiency, because standard tests of iron status are affected by it. Soluble transferrin receptors (sTfR) measurement and the calculation of the sTfR/ log ferritin index (sTfR index) are recommended, but data about diagnostically significant levels of these indicators in patients with spondyloarthritis (SpA) is currently limited.

Objectives: To assess the diagnostic significance of sTfR and the sTfR index for detecting absolute iron deficiency in patients with SpA and anemia.

Methods: Complete blood count, standart iron metabolism parameters, C-reactive protein (CRP) and erythrocyte sedimentation rate (ESR) were evaluated in 68 patients with SpA. Serum concentration of STfR was measured with enzymelinked immunosorbent assay (ELISA) using sTfR ELISA kit («Monobind Inc.», USA). The sTfR index was calculated by the formula sTfR/ $\log _{10}$ ferritin. Anemia was defined using the World Health Organization criteria. Depending on the serum ferritin concentration, transferrin saturation, and CRP level, ACD, IDA, or combined anemia (ACD/IDA) were diagnosed. Disease activity was determined by the BASDAI (Bath Ankylosing Spondylitis Disease Activity Index) and ASDASCRP (Ankylosing Spondylitis Disease Activity Score based on CRP) scales. Receiver operating characteristic $(\mathrm{ROC})$ analysis was performed with MedCalc. Results: Anemia was found in 48 of $68(70,6 \%)$ SpA patients. $16(33,3 \%)$ patients had ACD and 32 (66,7\%) had ACD/IDA. Hemoglobin level in ACD was 118 [112; 123] g/L, in ACD/IDA - 110 [106; 120] g/L, in non-anemic patients - 133 [129; 145] g/L ( $p<0.001$ for all groups). CRP and ESR values were higher in ACD compared to ACD/IDA patients (31.5 [20.3; 46.4] mg/L and $27.0[16.0 ; 35.5] \mathrm{mm} / \mathrm{h}$ versus $9.8[5.6 ; 16.9] \mathrm{mg} / \mathrm{L}$ and 15.5 $[12.0 ; 22.5] \mathrm{mm} / \mathrm{h}$, respectively $[\mathrm{p}=0.00$ and $\mathrm{p}=0.038])$. No statistically significant difference was found between all groups in BASDAI and ASDAS-CRP scores.

ACD/IDA patients had significant increases in serum sTfR levels $(1.7[1.4 ; 2.2]$ $\mathrm{mg} / \mathrm{L})$ compared to $\operatorname{ACD}(1.5[1.1 ; 1.7] \mathrm{mg} / \mathrm{L}, \mathrm{p}=0,04)$ and to non-anemic patients $(1,3[1,1 ; 1,6] \mathrm{mg} / \mathrm{L}, \mathrm{p}=0,003)$. The sTfR index was significantly higher in ACD/ IDA $(0.93$ [0.82; 1.24]) compared to patients with ACD $(0.64$ [0.48; 0.75], $\mathrm{p}<0.001)$ and without anemia $(0.67[0.56 ; 0.81], p<0.001)$.

The areas under the curves (AUCs) for distinguishing between ACD/IDA and ACD were 0.85 for $s$ TfR index $(p<0,001), 0.72$ for $\operatorname{sTfR}(p<0,001)$. The $s$ TfR index (cutoff $>0.83$ ) and sTfR (cutoff $>1.39 \mathrm{mg} / \mathrm{L}$ ) had sensitivities of $75 \%$ and $53 \%$, and specificities of $83 \%$ and $81 \%$, respectively.

Conclusion: According to obtained data, serum concentration of STfR $>1.39 \mathrm{mg} / \mathrm{L}$ and the sTfR index $>0.83$ point to the presence of iron deficiency component in the structure of anemic syndrome in patients with $\mathrm{SpA}$.

References: Management of patients with SpA requires constant monitoring of side effects of therapy, in particular induced by the non-steroidal anti-inflammatory drugs. Use of sTfR and the sTfR index can improve the detection of IDA. A significant advantage of these indicators is their independence from systemic inflammation.

Disclosure of Interests: None declared

DOI: 10.1136/annrheumdis-2020-eular.3608 \begin{tabular}{|l|l}
\hline AB0721 & OCULAR INVOLVEMENT IN INFLAMMATORY BOWEL \\
DISEASE. STUDY OF 1442 PATIENTS FROM A SINGLE
\end{tabular} DISEASE. STUDY OF 1442 P
UNIVERSITARY CENTER.

L. Sanchez-Bilbao ${ }^{1}$, D. Martinez-Lopez ${ }^{1}$, I. González-Mazón ${ }^{1}$, M. J. GarcíaGarcía $^{2}$, M. Rivero-Tirado ${ }^{2}$, B. Castro ${ }^{2}$, J. Crespo², M. A. González-Gay ${ }^{1}$,

R. Blanco ${ }^{1} .{ }^{1}$ H.U. Marqués de Valdecilla, Rheumatology, Santander, Spain; ${ }^{2}$ H.U. Marqués de Valdecilla, Gastroenterology, Santander, Spain

Background: Inflammatory bowel disease (IBD), which includes Crohn's disease (CD), and Ulcerative colitis (UC) are related to Spondyloarthritis ( $\mathrm{SpA}$ ). Ocular manifestations (OM) are well-stablished in SpA but not in IBD. It has been classically reported that whereas uveitis with $\mathrm{SpA}$ is predominantly anterior, unilateral, sudden, and limited; in IBD it is bilateral, posterior, insidious, and chronic (Lyons \& Rosenbaum JT. Arch Ophthalmol 1997; 115:61-4).

Objectives: In a large unselected series of IBD, we study the OM and assess; a) epidemiological, clinical features, b) the relationship with extraintestinal manifestations.

Methods: Study of all consecutive patients from a single University Hospital during the last 40 years with: a) IBD (CD and $\mathrm{UC}$ ), and b) OM: uveitis and scleral pathology diagnosed by clinical features and slit-lamp.

Results: OM were present in 42 (2.9\%) (25 women/17 men) (84 eyes) of 1442 IBD patients; OM included the uveitis group (UG) $(n=23 ; 1.6 \%)$ and the scleral pathology group (SG) $(n=19,1.32 \%)$ (TABLE).

TABLE.

\begin{tabular}{|c|c|c|c|}
\hline & $\begin{array}{l}\text { Uveitis } \\
(n=23)\end{array}$ & $\begin{array}{c}\text { Epi/scleritis } \\
(n=19)\end{array}$ & $\mathbf{p}$ \\
\hline \multicolumn{4}{|l|}{ DEMOGRAPHIC PARAMETERS } \\
\hline Sex, n (\%) & $6 \% / 17 \%$ & $11 \sigma^{\circ / 8}$ \% & $p=0.04^{*}$ \\
\hline $\begin{array}{l}\text { Age at diagnosis (years) mean } \pm \mathrm{SD} \\
\text { INTESTINAL AFFECTION }\end{array}$ & $49.13 \pm 14.64$ & $47.63 \pm 12.48$ & $p=0.415$ \\
\hline $\mathrm{CD}, \mathrm{n}(\%)$ & $12(52.17)$ & $16(84.21)$ & $p=0.02^{*}$ \\
\hline UC, $n(\%)$ & $11(47,83)$ & $3(15,74)$ & $p=0.16$ \\
\hline \multicolumn{4}{|l|}{ EXTRAINTESTINAL AFFECTION } \\
\hline Cutaneous manifestations & & & \\
\hline -Erythema nodosum, n (\%) & $6(26.09)$ & $2(10.53)$ & $p=0.30$ \\
\hline -Pyoderma gangrenosum, $n(\%)$ & $1(4.35)$ & $0(0)$ & $p=0.92$ \\
\hline -Psoriasis, n (\%) & $1(4.35)$ & $4(21.01)$ & $p=0.23$ \\
\hline Joint involvement & $10(43.50)$ & $6(31.60)$ & $p=0.36$ \\
\hline -Psoriathic arthritis, $\mathrm{n}(\%)$ & $1(4.35)$ & $3(15.80)$ & $\mathrm{p}=0.47$ \\
\hline -Enteropathic Spondyloarthritis, n (\%) & $6(26.09)$ & $3(15.80)$ & $p=0.66$ \\
\hline -Ankylosing Spondylitis, n (\%) & $3(13.04)$ & $0(0)$ & $p=0.28$ \\
\hline \multicolumn{4}{|l|}{ Digestive manifestations } \\
\hline •NASH, n(\%) & $4(17.39)$ & $6(31.58)$ & $p=0.28$ \\
\hline
\end{tabular}

${ }^{*} \mathrm{p}$ value $<0.05$. SD: standard deviation; CD: Crohn's disease; UC: ulcerative colitis; NASH: non-alcoholic steatohepatitis.

The most common pattern in SG was episcleritis $(n=16 ; 84.21 \%)$ and scleritis $(n=3)$. In UG, uveitis was typically anterior $(n=18 ; 78.3 \%)$, unilateral $(n=19$; $82.6 \%)$, sudden $(n=19 ; 82.6 \%)$, and limited $(n=12 ; 52.2 \%)$.

The comparative study between SG vs UG showed in UG a significant predominance of women and UC. Also, a non-significative higher frequency in Pyoderma gangrenosum, erythema nodosum and joint involvement was observed in UG. After a mean follow-up of $15.2 \pm 9.97$ years, extraintestinal manifestations were observed in $100 \%$ of patients, being articular forms ( $n=16 ; 38.10 \%$ ) the most common type. In addition, joint/axial flare is more related to the presence of uveitis $(p=0.038)$. Conclusion: Both uveitis and episcleritis are equally frequent $\mathrm{OM}$ in IBD. Although uveitis is more infrequent in IBD than in SpA, it is also anterior, unilateral, sudden and limited in contrast with published data from selected series. References:

[1] Lyons \& Rosenbaum JT. Arch Ophthalmol 1997; 115:61-4

Disclosure of Interests: Lara Sanchez-Bilbao Grant/research support from: Pfizer David Martinez-Lopez: None declared, Iñigo González-Mazón: None declared, María José García-García: None declared, Montserrat Rivero-Tirado: None declared, Beatriz Castro: None declared, Javier Crespo: None declared, Miguel A González-Gay Grant/research support from: Pfizer, Abbvie, MSD, Speakers bureau: Pfizer, Abbvie, MSD, Ricardo Blanco Grant/research support from: AbbVie, MSD, and Roche, Speakers bureau: AbbVie, Pfizer, Roche, Bristol-Myers, Janssen, and MSD DOI: 10.1136/annrheumdis-2020-eular.4612

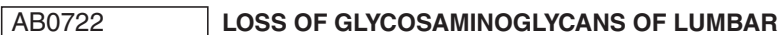 INTERVERTEBRAL DISCS IN PATIENTS WITH ANKYLOSING SPONDYLITIS}

P. Sewerin ${ }^{1}$, D. Abrar ${ }^{2}$, M. Frenken ${ }^{2}$, X. Baraliakos ${ }^{3}$, M. Schneider ${ }^{1}$, B. Ostendorf ${ }^{1}$, C. Schleich ${ }^{2} .{ }^{1}$ Heinrich-Heine University, Department for Rheumatology, Duesseldorf, Germany; ${ }^{2}$ Heinrich-Heine University, Institute 